\title{
Fate of Emphysematous Pyelonephritis: A Single Center Study
}

\author{
Muhammad Naeem, Riaz Ahmad Khan,Ghaffar Shah, Asad Shamsher, Bakhtawar Gul.
}

\begin{abstract}
Background: Emphysematous Pyelonephritis (EPN) is a Urological emergency. It is a gas forming infection of the renal parenchyma and also involves the perirenal fat. It affects persons having Diabetes Mellitus specifically females.

Objectives: To present clinical features, and compare abnormal laboratory investigations among poor and good outcome in patients affected by emphysematous pyelonephritis.

Materials and methods: This retrospective study was conducted in Institute of Kidney Diseases Hayatabad Peshawar on records of 50 patients affected by EPN. Patients having age from 35 to 85 years, clinical feature of upper urinary tract infections, and gas accumulation in renal parenchyma seen on computed tomography (CT) scan were included in the study. Age, sex, control of glucose status and abnormal laboratory investigations were recorded. Outcome was measured as poor or good. Data analysis was done in SPSS version 22.

Results: The mean age was $63.1 \pm 11.48$ years and $62 \%$ were females. The clinical features in patients with $E P N$ was fever $(n=37$, $74 \%)$ Flank, abdomen, or back pain $(n=34,68 \%)$. Urine analysis showed that pyuria was common $(n=35,70 \%)$ followed by severe proteinuria $(n=31,62 \%)$. Macrohematuria was found in $19(38 \%)$, thrombocytopenia in $24(48 \%)$ and leukocytosis in $28(56 \%)$ patients. In $35(70 \%)$ patients $\mathrm{HbA} 1 \mathrm{C}$ was $>8 \%$ of which $6(12 \%)$ died $(\mathrm{P}=.021)$. In $32(64 \%)$ the outcome was good.

Conclusion: Emphysematous Pyelonephritis affects females more than males. Most common abnormal laboratory findings are leukocytosis, thrombocytopenia and $\mathrm{HbAIC}>8 \%$. EPN is a fatal disease so quick management is required.
\end{abstract}

Keywords: Emphysematous Pyelonephritis, Diabetes Mellitus, Pyuria, Proteinuria, Macrohematuria.

This article may be cited as: Naeem M, Khan RA, Shah G, Shamsher A, Gul B . Fate of Emphysematous Pyelonephritis: A Single Center Study. J Saidu Med Coll Swat 2021;11(4):191-5.DOI:https://doi.org/10.52206/jsmc.2021.11.4.677

\section{INTRODUCTION}

Emphysematous pyelonephritis (EPN) is a disease in which there is gas in the renal parenchyma, collecting system or peri-nephric tissues leading to acute severe necrotizing infection. ${ }^{1}$ In 80 to $96 \%$ of cases affected by EPN diabetes mellitus is present, and in 22 to $66 \%$ hydronephrosis associated with urinary tract obstruction is found. ${ }^{2,3}$ Nonetheless EPN can be associated with kidney stones and neoplasms in those cases who are immuno-compromised. ${ }^{4}$ Emphysematous pyelonephritis affecting more females than males with female to male ratio of $3: 1^{5}$

The common clinical features in patients with EPN are fever with chilling, abdominal or flank pain, nausea, vomiting, dyspnea, acute renal impairment, altered sensorium, shock, and thrombocytopenia. ${ }^{6}$ Diagnosis of EPN involves proper history, examination and laboratory investigations. Ultrasound, plain radiograph and CT scan. ${ }^{7}$ The diagnostic sensitivity for EPN with plain radiograph is $65 \%$, ultrasound is $69 \%$, and CT scan is $100 \%{ }^{8}$ On CT scan the findings for EPN are the enlargement and destruction of renal

Urology Institute of Kidney Diseases,

Hayatabad Medical Complex, Peshawar Pakistan.

Correspondence: Dr. Muhammad Naeem

Associate Professor Urology Institute of Kidney Diseases,

Hayatabad Medical Complex, Peshawar Pakistan.

E-mail:mnaeem04@yahoo.com

Received: December 01 ${ }^{s t}, 2020$ Accepted: June $23^{r d}, 2021$ parenchyma, presence of gas in renal parenchyma, collection of fluid and necrotic foci or abscesses. ${ }^{9}$ It shows that computed tomography is of great importance and has great contribution in the diagnosis of EPN. ${ }^{10}$

Management of EPN spreads over a wide spectrum. The most conservative approach of managing EPN is resuscitation vigorously, treatment with antibiotic and good control of glycemic level. The invasive approaches involved urinary drainage by percutaneous nephrostomy (PCN) and nephrectomy in cases not responding to conservative treatment. ${ }^{11}$

Very little literature is available on clinical features, and treatment outcome of EPN in our province KPK, Pakistan. Ali et al. ${ }^{12}$ reported only a review of 6 cases affected with emphysematous pyelonephritis. Our study is relatively of large sample size of 50 cases which can provide detailed statistics for clinicians. Institute of Kidney Disease is major renal health facility with expert clinicians in our province so this study will give detailed insights to other renal health providers.

The aim of our study is to present clinical features, abnormal laboratory investigations and compare abnormal laboratory investigations among poor and good outcome in patients affected by EPN. 


\section{MATERIALAND METHODS}

This retrospective study was conducted on records of 50 patients affected by EPN admitted in the Department of Urology IKD, Hayatabad, Peshawar from $1^{\text {st }}$ January 2017 to $30^{\text {th }}$ June 2020. Written approval was taken from the hospital ethical review committee with diary no 609/Urol/IKD dated 13/10/2020.

The inclusion criteria was age range from 35 to 85 years, clinical feature of upper urinary tract infections (fever, positive urine culture, pus discharge in urine without recognized infections foci), and gas accumulation in renal parenchyma, or perinephric or pararenal space seen on CT scan. The exclusion criteria was the presence of fistula between bowel and urinary tract, history of recent trauma, recent urinary catheter insertion or drainage.

Age, sex, control of glucose status, shock, and urinary obstruction was recorded. Glucose status control was assessed by glycosylated hemoglobin level $(\mathrm{HbA} 1 \mathrm{C}) . \mathrm{HbA} 1 \mathrm{C}>8 \%$ was considered poor diabetic control. ${ }^{3}$ Leukocytosis $\left(>12 \times 10^{9} / \mathrm{L}\right.$ white blood cells count), thrombocytopenia $(<120 \times$ $10^{\circ} / \mathrm{L}$ platelet count), macrohematuria (RBCS in urine $>100$ per high power field), Severe proteinuria (urinary proteins $>3 \mathrm{~g} / \mathrm{L}$ on 2 occasions) were recorded.

CT scan of abdomen was taken for all participants. Percutaneous nephrostomy drainage (PCN) was inserted into renal or extra renal lesion under Ultrasound guidance. PCN was labeled failed if there was a progressive or persistent lesion with clinical manifestations of shock or prolonged fever after procedure.

We divided the outcome into two groups; "good" and "poor". Good outcome was assigned to those cases that were managed successfully only with antibiotics or PCN drainage combined with antibiotics while poor outcome was assigned to those whose PCN was unsuccessful and ended with nephrectomy or mortality.

Data analysis was done in SPSS version 22. Descriptive statistics were calculated as mean \pm SD for continuous variables like age and percentages for categorical variables like gender, clinical features, urine analysis and laboratory investigations. Fisher's Exact Test under two tailed hypothesis was applied to compare laboratory investigations among outcome (survived or died and good or poor). $\mathrm{P}=0.05$ was considered as significant.

\section{RESULTS}

Of total 50 cases $31(62 \%)$ were females and $19(38 \%)$ were males. The mean age was $63.1 \pm 11.48$ years with age ranged from 35 to 85 years. The most common clinical feature in patients with emphysematous pyelonephritis was fever $(n=37,74 \%)$ followed by Flank, abdomen, or back pain $(n=34,68 \%)$. Dyspnea was found in $7(14 \%)$, nausea or vomiting in $11(22 \%)$ and shock in $22(44 \%)$ cases. Urine analysis of patients with emphysematous pyelonephritis showed that pyuria was common $(n=35,70 \%)$ followed by severe proteinuria $(n=31,62 \%)$. Macrohematuria was found in $19(38 \%)$ patients. Laboratory investigations showed that $24(48 \%)$ patients were affected by thrombocytopenia and $28(56 \%)$ by leukocytosis. In $35(70 \%)$ patients $\mathrm{HbA} 1 \mathrm{C}$ was greater than $8 \%$.

In $32(64 \%)$ cases the outcome was good while in $18(36 \%)$ the outcome was poor. Of total $44(88 \%)$ survived while $6(12 \%)$ patients with emphysematous pyelonephritis died.(Table 01)

Table 1. Frequency of outcome and survival in patients with EPN.

\begin{tabular}{|c|c|c|c|}
\hline \multicolumn{2}{|c|}{} & Frequency & Percent (\%) \\
\hline \multirow{3}{*}{ Outcome } & Good & 32 & 64.0 \\
\cline { 2 - 4 } & Poor & 18 & 36.0 \\
\hline \multirow{2}{*}{ Survival } & Survival & 44 & 88 \\
\cline { 2 - 4 } & Mortality & 6 & 12 \\
\hline
\end{tabular}


$\mathrm{HbA1C}$ was statistically more than $8 \%$ in those who died due to emphysematous pyelonephritis than those who survived but the results were not statistically significant $(P=.087)$. Urinary tract obstruction was also not statically different between the two outcome for survival $(P=0.971)$. (Table 02).

Table 2. Comparison of laboratory investigations among outcome for survival

\begin{tabular}{|c|c|c|c|c|}
\hline \multicolumn{2}{|c|}{} & \multicolumn{2}{|c|}{ Outcome for Survival } & \\
\cline { 3 - 4 } & & Survival & Mortality & \multirow{2}{*}{ P-value* $^{*}$} \\
\cline { 3 - 4 } & $\mathbf{n}(\%)$ & $\mathbf{n}(\%)$ & \\
\hline \multirow{2}{*}{$\begin{array}{c}\text { Glycosylated hemoglobin A1C } \\
>0.08\end{array}$} & Yes & $29(82.9)$ & $6(17.1)$ & \multirow{2}{*}{.087} \\
\cline { 2 - 4 } & No & $15(100)$ & $0(0)$ & \multirow{2}{*}{.971} \\
\hline \multirow{2}{*}{\begin{tabular}{c} 
Urinary tract obstruction \\
\cline { 3 - 4 }
\end{tabular}} & Yes & $15(88.2)$ & $2(11.8)$ & \\
\cline { 2 - 4 } & No & $29(87.9)$ & $4(12.1)$ & \\
\hline
\end{tabular}

"Fisher's Exact Test

Similarly only $\mathrm{HbA} 1 \mathrm{C}$ more than $8 \%$ was statistically significant in patients with poor than good outcome $(P=0.005)$. Urinary tract obstruction was not statically different between the two outcomes $(P>0.05)$. (Table 03)

Table 3.

Comparison of laboratory investigations among good and poor outcome affected by EPN

\begin{tabular}{|c|c|c|c|c|}
\hline \multirow{2}{*}{} & \multicolumn{2}{|c|}{ Outcome } & \multirow{2}{*}{ P-value* $^{*}$} \\
\cline { 3 - 4 } & Good & Poor & \\
\hline \multirow{2}{*}{$\begin{array}{c}\text { Glycosylated hemoglobin A1C } \\
>0.08\end{array}$} & Yes & $18(51.4)$ & $17(48.6)$ & \multirow{2}{*}{.005} \\
\cline { 2 - 4 } & No & $14(93.3)$ & $1(6.7)$ & \\
\hline \multirow{2}{*}{\begin{tabular}{c} 
Urinary tract obstruction \\
\cline { 2 - 4 }
\end{tabular}} & Yes & $12(70.6)$ & $5(29.4)$ & \multirow{2}{*}{.548} \\
\cline { 2 - 4 } & No & $20(60.6)$ & $13(39.4)$ & \\
\hline
\end{tabular}

\section{DISCUSSION}

The current study was aimed to present clinical features, abnormal laboratory investigations and compare abnormal laboratory investigations among poor and good outcome in patients affected by EPN. The baseline features of patients with emphysematous pyelonephritis at initial presentation were fever, flank, abdomen, or back pain, dyspnea, nausea, vomiting, and shock. On urine analysis pyuria, severe proteinuria and macrohematuria was present. Laboratory investigations showed that leukocytosis, thrombocytopenia and $\mathrm{HbA} 1 \mathrm{C}$ greater than $8 \%$ was found. In $36 \%$ the outcome was poor in which percutaneous nephrostomy (PCN) drainage was unsuccessful and end with nephrectomy or patient died. Similarly $\mathrm{HbA} 1 \mathrm{C}$ more than $8 \%$ was not statistically more in those who died due to emphysematous pyelonephritis than those who survived $(P=.087)$.

Our results showed that females were more affected by EPN than males. This can be due to more occurrences of urinary tract infection and ultimately urinary tract obstruction in females. Similar results were found in previous studies. ${ }^{5,13,15}$ Ideguchi et al. ${ }^{5}$ reported that emphysematous pyelonephritis affecting more females than males with female to male ratio of 3:1. Thomas et al. ${ }^{13}$ reviewed literature of 135 cases and found that 
$64 \%$ females were more affected by EPN. Other studies conducted in India on EPN reported that $62 \%$ and $59 \%$ were female. ${ }^{7,14}$

Our findings showed that mean age was $63.1 \pm 11.48$ years with age ranging from 35 to 85 years. Huang et al. ${ }^{3}$ published a large sample size study on 48 cases affected by EPN and reported that mean age was 60 years with range of 37 to 83 years. Another retrospective review of 10 cases affected with EPN reported that mean age was 59.8 years and age range was 47 to 84 years. ${ }^{13}$ These results are in consistent with our findings.

Our results revealed that fever $(74 \%)$ was most common features followed by flank, abdomen, or back pain $(68 \%)$. In $44 \%$ cases shock was present. A study conducted on EPN in Indian population on 74 cases in which 62 were respondent reported that the common feature was fever followed by abdominal and flank pain. ${ }^{7}$ Huang et al. ${ }^{3}$ conducted a study on 48 cases with EPN in Taiwan and reported that fever (79\%) was most common features followed by flank, abdomen, or back pain (71\%). Shock was present in $29 \%$ cases. Aboumarzouk et al. ${ }^{16}$ applied Cochrane guidelines to systematically review studies published from 1980 to 2013. Their results showed that fever were present in $74.7 \%$ and flank pain in $70.4 \%$ and shock in $54.4 \%$ cases. These results are closure to our study.

The urine analysis of patients with EPN in our sample showed that pyuria was present in $70 \%$, severe proteinuria in $62 \%$, and macrohematuriain $38 \%$. In Haung et al. ${ }^{3}$ study the pyuria was present in $79 \%$, severe proteinuria in $21 \%$, and macrohematuria in $13 \%$. The difference can be due to laboratory standard values, reagents used and patients variability.

The current study showed that in $36 \%$ the outcome was poor in which percutaneous nephrostomy (PCN) drainage was unsuccessful and ended with nephrectomy or patient died. Huang et al. ${ }^{3}$ used same operational definition of 'poor outcome' and reported that poor outcome was present in $34.47 \%$. Another study conducted in India reported that out of total 26 cases with EPN, 3(11.5\%) had poor outcome (2 PCN unsuccessful and 1 died). ${ }^{17}$ The difference in results can be due to difference in disease severity, provided health care facilities, genetic and ethnic variability.
We compared two parameter between good and poor outcome; Glycosylated hemoglobin A1C more than $8 \%$ and urinary tract obstruction. None of the results were statistically significant. Haung et al. ${ }^{3}$ made such type of comparison and reported that there was no statistical difference for any of these parameters. These results are similar to our study.

In our study the mortality rate was $12 \%$ i.e. 6 cases died out of 50 patients. Aboumarzouk et al. ${ }^{16}$ conducted a systematic review in 2014 on studies published from 1980 to 2013 and finally included 32 studies in their qualitative analysis. Their results showed that combined mortality rate was $18 \%$. So our mortality rate is lower than international studies. Recently a small sample size study was conducted on 20 cases with EPN in Karachi by Irfaan et al. ${ }^{18}$ reported zero percent mortality in EPN cases. Their results also showed that most of the patients were managed with conservative therapy. The difference can be due to the fact that in our center most of the patients are in end stage of the disease and referred later from secondary and primary care center so our mortality rate can be higher.

\section{CONCLUSION}

EPN affects females more than males. Most common abnormal laboratory findings are leukocytosis, thrombocytopenia and $\mathrm{HbAIC}>8 \%$. EPN is a fatal disease so quick management is required.

\section{REFERENCES}

1. Hayashi T, Yanaihara H, Kaguyama H, Hanashima $F$, Sakamoto H, Nakahira Y, et al. Emphysematous pyelonephritis with successful renal preservation using open drainage surgery: A case report. Urol Case Rep 2018;17:76-81.

2. Ruiz A, Fabre C, Boutault J, Merzeau C. Pyélonéphrite emphysémateuse. J Imag Diagn Interven 2018;1(3):172-3.

3. Huang JJ, Tseng CC. Emphysematous pyelonephritis: clinicoradiological classification, management, prognosis, and pathogenesis. Arch Inter Med 2000;160(6):797-805.

4. Kim CS, Ma SK, Kim SW. Bilateral emphysematous pyelonephritis. J Korean Med Sci 2017;32(11):1736-7.

5. Ideguchi S, Yamamoto K, Ikeda A, Hashimoto K, Takazono T, Saijo T, et al. A case of bilateral emphysematous pyelonephritis caused by Candida albicans. J Infect Chemother 2019;25(4):302-6.

6. Loupa CV, Gkeka M, Mitrakis G Emphysematous Pyelonephritis in a Diabetic Patient with Remarkable Radiological Findings and Excellent Outcome without Surgical Intervention or Drainage. Am J Case Rep 2020;21:e922974. 
7. Sokhal AK, Kumar M, Purkait B, Jhanwar A, Singh $\mathrm{K}$, Bansal A, et al. Emphysematous pyelonephritis: changing trend of clinical spectrum, pathogenesis, management and outcome. Turk J Urol 2017;43(2):202-9.

8. Somani BK, Nabi G, Thorpe P, Hussey J, Cook J, N'Dow J, et al. Is percutaneous drainage the new gold standard in the management of emphysematous pyelonephritis? Evidence from a systematic review. J Urol 2008;179(5):1844-9.

9. Craig WD, Wagner BJ, Travis MD. Pyelonephritis: radiologic-pathologic review. Radiograph 2008;28(1):255-76.

10. Tatakis FP, Kyriazis L, Panagiotopoulou LE, Kalafatis E, Mantzikopoulos G, Polyzos K, et al. Simultaneous Diagnosis of Emphysematous Osteomyelitis and Emphysematous Pyelonephritis in a Diabetic Patient Am J Case Rep 2019; 20:179396.

11. Sharma PK, Sharma R, Vijay MK, Tiwari P, Goel A, Kundu AK. Emphysematous pyelonephritis: Our experience with conservative management in 14 cases. Urol Ann 2013;5(3):157-60.

12. Ali SN, Ahmed N, Naushad A, Naushad M. Emphysematous pyelonephritis: a review of six cases. J Ayub Med CollAbbott 2014;26(4):591-7.

13. Thomas AA, Lane BR, Thomas AZ, Remer EM, Campbell SC, Shoskes DA. Emphysematous cystitis: a review of 135 cases. BJU Int 2007;100(1):17-20.

14. Lin W-R, Chen M, Hsu J-M, Wang C-H. Emphysematous pyelonephritis: patient characteristics and management approach. Urol Int 2014;93(1):29-33.

15. Karthikeyan VS, Manohar CMS, Mallya A, Keshavamurthy R, Kamath AJ. Clinical profile and successful outcomes of conservative and minimally invasive treatment of emphysematous pyelonephritis. Cent European J Urol. 2018; 71(2): 228-33.

16. Aboumarzouk OM, Hughes $\mathrm{O}$, Narahari $\mathrm{K}$, Coulthard R, Kynaston $\mathrm{H}$, Chlosta $\mathrm{P}$, et al. Emphysematous pyelonephritis: Time for a management plan with an evidence-based approach. Arab J Urol 2014;12(2):106-15.

17. Misgar RA, Mubarik I, Wani AI, Bashir MI, Ramzan M, L a w a y A . E m physe m a tous pyelonephritis: A 10-year experience with 26 cases.Indian J Endocr Metab 2016;20(4):475-80.

18. Irfaan AM, Shaikh NA, Jamshaid A, Qureshi AH. Emphysematous Pyelonephritis: A single center review. Pakistan J Med Sci 2020;36(1):S83-S86.
DATA SHARING STATEMENT: The data that support the findings of this study are available on request from the corresponding author. The data are not publicly available due to privacy or ethical restrictions.

CONFLICT OF INTEREST: Authors declared no conflict of interest.

GRANTED SUPPORT AND FINANCIAL DISCLOSURE: Nil

\section{AUTHOR'S CONTRIBUTION}

Following authors have made substantial contributions to the manuscript as under

Naeem M, Khan RA:

Concept and design of study, Collection of data, statistical analysis

Shah G:

Shamsher A: Writing of manuscript, critical review of manuscript Analysis and interpretation of data, statistical analysis

GulB: Data collection, bibliography

Authors agree to be accountable for all aspects of the work in ensuring that questions related to the accuracy or integrity of any part of the work are appropriately investigated and resolved. 